\title{
Assessing uncertainties in climate change impacts on runoff in Western Mediterranean basins
}

\author{
D. Ruelland ${ }^{1}$, P. Hublart ${ }^{2}$, and Y. Tramblay ${ }^{3}$ \\ ${ }^{1}$ CNRS, HydroSciences Laboratory, Montpellier, France \\ ${ }^{2} \mathrm{UM}$, HydroSciences Laboratory, Montpellier, France \\ ${ }^{3}$ IRD, HydroSciences Laboratory, Montpellier, France \\ Correspondence to: D. Ruelland (denis.ruelland@um2.fr)
}

Received: 11 March 2015 - Accepted: 11 March 2015 - Published: 12 June 2015

\begin{abstract}
This paper investigates the uncertainties linked to climate change impacts on runoff in four mesoscale basins ( 900 to $1800 \mathrm{~km}^{2}$ ) in the Mediterranean region. Runoff simulations were based on a daily conceptual model including a snow module. The model was calibrated and validated according to a differential split-sample test over a 20-year period and four competing criterions aiming to represent model structural uncertainty based on the concept of Pareto optimality. Five regional climate models (RCMs) from the Med-CORDEX initiative were used to provide temperature and precipitation projections under RCP8.5 by 2050 . The RCMs' inability to realistically simulate reference climate (notably precipitation) led us to apply a monthly perturbation method in order to produce a range of climate scenarios. The structural uncertainty bounds obtained from the hydrological simulations over the reference period showed that the model was able to correctly reproduce observed runoff despite contrasted hydrological conditions in (and in between) the basins. Climate projections were shown to be convergent regarding temperatures, which could increase by about +1 to $3{ }^{\circ} \mathrm{C}$ on each basin. In contrast, no clear trends in precipitation could be put in evidence, some RCMs leading to a mean annual precipitation decrease (up to $64 \%$ ), and others to an increase (up to $33 \%$ ). The hydrological projections resulted from the combination of the hydrological simulation bounds with the range of climate projections. Despite the propagation of those uncertainties, the 2050 hydrological scenarios agreed on a significant runoff decrease (2-77\%) during spring on all basins. On the opposite, no clear trend in runoff could be observed for the other seasons.
\end{abstract}

\section{Introduction}

Quantitatively assessing the uncertainties associated with hydrological projections is a difficult task, even if qualitatively it is now recognized that these uncertainties are considerable. They stem from the methods used to generate climate projections as well as from hydrological modelling.

Due to the stochastic nature of weather systems, climate models are not able to reproduce single events but rather statistical properties of the future climate (called projections). Acknowledging the large differences between projections from different climate models, ensemble modelling has been standard among climate modelers for the last two decades (Van der Linden and Mitchell, 2009; Taylor et al., 2012). From different ensemble model experiments, it is generally concluded that the ensemble average provides a better repre- sentation of the current climate than any single climate model (Gleckler et al., 2008). The ensemble is therefore expected to provide a more robust projection of the future climate. In addition, it provides an estimate of the associated projection uncertainty (Wilby and Dessai, 2010).

Common sources of uncertainty in hydrological modelling in stationary conditions (in terms of climate conditions and/or physical characteristics) include errors in model structure, problems in the calibration procedure, and errors in the data used for calibration/validation (e.g. Hublart et al., 2014). In non-stationary conditions, as in climate change studies, additional uncertainties arise from parameter instability due to possible changes in the physical basin characteristics and in the dominant processes (see e.g. Brigode et al., 2013; Coron et al., 2012, 2014). In both cases, model 


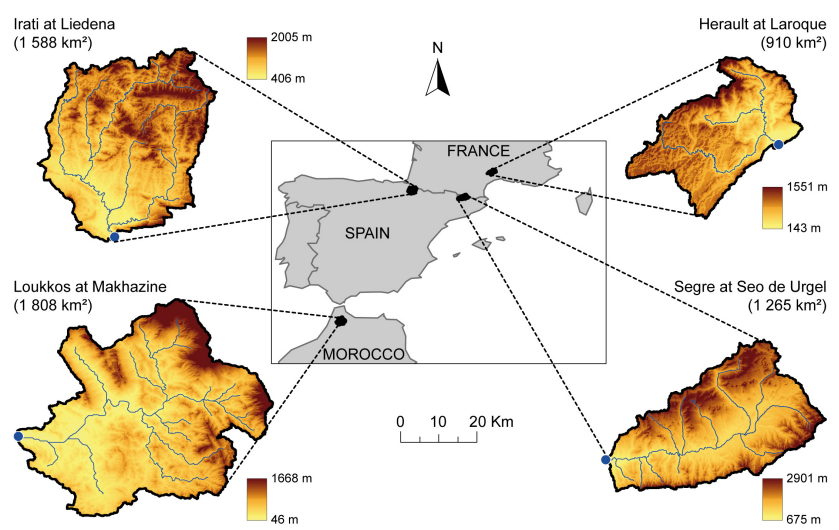

Figure 1. Studied basins: location in the Western Mediterranean and topography.

structure errors (structural uncertainty) and the identification of model parameters (parameter uncertainty) are generally considered as the two main sources of uncertainty in hydrological modelling.

Each source of uncertainty was already analyzed in the context of changing climate, but few studies (see e.g. Chen et al., 2011; Teng et al., 2012) have assessed their relative importance. This paper thus aims to investigate the propagation of uncertainty from climate projections to hydrological modelling in the assessment of climate change impact on runoff. It was motivated by the availability of new highresolution climate simulations from the Med-CORDEX exercise on the Mediterranean region and by the recent findings (see e.g. Refsgaard et al., 2014) on the difficulties for hydrological model parameters to adapt to contrasted climate conditions. To further investigate this issue, we propose a diagnostic approach based on a common assessment protocol applied on Mediterranean basins with similar surface areas and presenting a large range of hydro-meteorological situations. Ultimately, we aim at evaluating whether a clear change signal of the possible future runoff can be put in evidence by 2050 in Western Mediterranean.

\section{Material and methods}

\subsection{Study areas and hydro-climatic data}

Four mesoscale basins (910 to $1800 \mathrm{~km}^{2}$ ) have been selected along a North-South climate gradient in Western Mediterranean (Fig. 1): the Hérault at Laroque (France), the Irati at Liedena, (Spain), the Segre at Seo de Urgel (Spain) and the Loukkos at Makhazine (Morocco). These basins are located upstream from storage-dams and in areas where withdrawals are negligible. Consequently their streamflow regime can be considered as natural.

Preliminary studies (Fabre et al., 2015; Tramblay et al., 2013) provided daily hydro-climatic data (precipitation, temperature and streamflow) with few gaps over a common 20- year period (1986-2005), thus allowing comparison between basins. For the Hérault basin, climate forcings were extracted from the SAFRAN $8 \times 8 \mathrm{~km}$ meteorological analysis system (Quintana-Segui et al., 2008) and observed runoff was provided by the French Ministry of Ecology and Sustainable Development's database Banque Hydro. For the Irati and Segre basins, climate forcings were obtained by interpolating daily precipitation and temperature measurements on an $8 \times 8 \mathrm{~km}$ grid with the inverse distance weighted method. The precipitation and temperature data were extracted from respectively 818 and 264 stations available at the Ebro basin scale. Elevation effects on temperature distribution were considered using a digital elevation model and a lapse rate of $-6.65^{\circ} \mathrm{C} \mathrm{km}^{-1}$ estimated from the data. Daily streamflow data were provided by the Center of studies and experiments on hydraulic systems (CEDEX). On the Loukkos catchment, precipitation data were interpolated based on 11 stations using the IDW method on a $5 \times 5 \mathrm{~km}$ grid. Since daily temperature data were only available from a station located at the basin outlet, a universal lapse rate of $-6.5^{\circ} \mathrm{C} \mathrm{km}^{-1}$ was considered for temperature interpolation. Hydro-climatic data including daily streamflow were provided by the DPRE (Département de Planification des Ressources en Eau) of Morroco.

Due to the lack of additional data on the Moroccan basin, a simple formula relying on solar radiation and temperature was selected (Oudin et al., 2005) for assessing daily potential evapotranspiration (PE) on each basin.

\subsection{Hydrological model}

Streamflow was simulated in the basins using the GR $4 \mathrm{j}$ conceptual model (Perrin et al., 2003). This hydrological model relies on precipitation $(P)$ and $\mathrm{PE}$ inputs and is run at a daily time step according to four free parameters. A threeparameter snow module based on catchment-averaged areal temperature (Ruelland et al., 2011, 2014) was added and activated in the snow-affected basins (Irati and Segre).

\subsection{Multi-objective optimization}

Calibration of the model parameters and analysis of the simulation performances were conducted by comparing simulated and observed streamflow at a 10-day time step within a multiobjective framework. The following objectives were considered: (i) the overall agreement of the shape of the hydrograph via the Nash-Sutcliffe Efficiency (NSE) metric; (ii) the agreement of the low flows via a modified, log version of the NSE criterion; and (iii) the agreement of the runoff volume via the cumulated volume error (VEC) and the mean annual volume error (VEM). 


$$
\begin{aligned}
& \text { Crit } 1=1-[\mathrm{NSE}]=1- \\
& \quad\left[1-\left\{\sum_{t=1}^{N}\left(Q_{\mathrm{obs}}^{t}-Q_{\mathrm{sim}}^{t}\right)^{2} / \sum_{t=1}^{N}\left(Q_{\mathrm{obs}}^{t}-\overline{Q_{\mathrm{obs}}}\right)^{2}\right\}\right] \\
& \text { Crit2 }=1-\left[\mathrm{NSE}_{\mathrm{log}}\right]=1-[1- \\
& \ldots-\log \left(Q_{\mathrm{sim}}^{t}+0.1\right)^{2} / \sum_{t=1}^{N} \\
& \left.\ldots-\log \left(\overline{Q_{\mathrm{obs}}}\right)\right)^{2} \\
& \text { Crit3 }=\left|\mathrm{VE}_{\mathrm{C}}\right|=\left|\sum_{y=1}^{N_{\text {years }}} V_{\mathrm{obs}}^{y}-\sum_{y=1}^{N_{\text {years }}} V_{\text {sim }}^{y} / \sum_{y=1}^{N_{\text {years }}} V_{\mathrm{obs}}^{y}\right| \\
& \text { Crit } 4=\mathrm{VE}_{\mathrm{M}}=\sum_{y=1}^{N_{\text {years }}}\left(\left|V_{\mathrm{obs}}^{y}-V_{\text {sim }}^{y}\right| / V_{\mathrm{obs}}^{y}\right) / N_{\text {years }}
\end{aligned}
$$

Where $Q_{\mathrm{obs}}^{t}$ and $Q_{\mathrm{sim}}^{t}$ are the observed and simulated discharges for the time-step $t, N$ is the number of time-steps with available observations, $V_{\mathrm{obs}}^{y}$ and $V_{\text {sim }}^{y}$ are the observed and simulated volumes for year $y$, and $N_{\text {years }}$ is the number of years of the simulation period.

These criteria reflect different and potentially competing objectives given the model's inability to simultaneously reproduce all aspects of the system behavior (see e.g. Hublart et al., 2014). In that case, many numerical solutions exist because of the trade-offs between these objectives. A Paretooptimal solution is achieved when it cannot be improved upon without degrading at least one of its objective criteria. The set of Pareto-optimal solutions was reduced by using cut-off thresholds to exclude non-acceptable trade-offs.

Among the various Pareto-optimal solutions retained the Best Compromise Solution (BCS) was considered as the one minimizing the following function:

$\gamma=(1-\mathrm{NSE})+\left(1-\mathrm{NSE}_{\log }\right)+\left|\mathrm{VE}_{\mathrm{C}}\right|+\mathrm{VE}_{\mathrm{M}}$.

The Non-dominated Sorted Genetic Algorithm II (NSGAII) (Deb et al., 2002) was selected to calibrate the hydrological model and identify the various optima solutions on each basin. This algorithm has the advantage of not needing any additional parameter (other than those common to all genetic algorithms, i.e. the initial population and the number of generations).

The model efficiency was evaluated following a differential split-sample test scheme (Klemeš, 1986) aiming to consider climatically contrasted sub-periods over a 20 -year simulation period (1986-2005): two sub-periods (here after called dry years and wet years) of equal length (10 driest years and 10 wettest years according to median annual precipitation over the period) were used alternatively for calibration and validation. This made it possible to test if the hydrological model calibrated on a given period was able to simulate streamflow with a similar efficiency on another period when it differs dramatically.

\subsection{Climate scenarios}

Five regional climate models (RCMs, Table 1) from the MedCORDEX initiative (http://www.medcordex.eu) were used to generate temperature, $\mathrm{PE}$ and precipitation projections. The RCMs' inability to realistically simulate reference climate (notably precipitation volume and seasonal patterns, not shown here for brevity's sake) led us to apply a basic unbiasing and downscaling technique in order to produce a range of high-resolution climate scenarios from the RCM outputs. All simulations of climate change were thus based on the historical Representative Concentration Pathway (RCP) over the reference period (1986-2005) and the scenario RCP8.5 at the 2050 horizon (2041-2060). The RCP8.5 was selected because it is characterized by the most pessimistic increasing greenhouse gas emissions over time. High-resolution climate change forcings were obtained by a monthly perturbation method, which assumes that climate models reproduce the relative change in climatic variables better than their absolute values. This method consists in producing future climate scenarios by simply modifying the observed climatic series so as to reproduce the mean monthly variations obtained between the reference and future climatic simulations from climate models. For more details on the method used, see Ruelland et al. (2012).

\section{Results}

\subsection{Hydrological model efficiency and uncertainties}

The uncertainty bounds obtained from the hydrological simulations over the reference period shows that the model was able to correctly reproduce observed runoff despite contrasted hydrological conditions in and in between the basins (Fig. 2). However, although the uncertainty bounds generally enclose mean seasonal observed runoff, they sometimes only bracket about $50 \%$ of observations when continuous simulations over multi-year periods are considered. As a result, if the hydrological model was able to reproduce rather accurately mean streamflow from the basins, it failed to capture all extreme events such as exceptional low or high flows. This means that its use must be limited to the analysis of mean shifts in the future and that it cannot be designed for analysing the impacts of potentially more intense drought or flood events.

Optimal parameter sets showed a relative dependence on the climate characteristics of the calibration period (not shown here). However, the model performance did not necessarily worsen over the validation period in comparison to the calibration period with contrasted climatic conditions (Fig. 2). Hence, the impact of the calibration period climate specificity on the simulated streamflow was not straightforward since for all basins studied, using a wet calibration sub-period for a dry validation sub-period did not generate a larger bias between observed and simulated flows than when 
Table 1. Name and origin of the five $50 \times 50 \mathrm{~km}$ Regional Climate Models (RCM) used in the study.

\begin{tabular}{llll}
\hline Regional Climate Model & Associated GCM & Acronym & Country \\
\hline $\begin{array}{l}\text { CMCC (Centro euroMedit. Sui } \\
\text { cambiamenti Climatici) }\end{array}$ & CMCC & CMCC/CMCC & Italy \\
\hline $\begin{array}{l}\text { CNRM (Centre National des } \\
\text { Recherches Météorologiques) }\end{array}$ & $\begin{array}{l}\text { ARPEGE (Action de Recherche } \\
\text { Petite Echelle Grande Echelle) }\end{array}$ & CNRM/ARPEGE & France \\
\hline $\begin{array}{l}\text { GUF (Goethe Universität } \\
\text { Frankfort) }\end{array}$ & MPI (Max Planck Institute) & GUF/MPI & Germany \\
$\begin{array}{l}\text { ICTP (International Centre of } \\
\text { Theoretical Physics) }\end{array}$ & MPI (Max Planck Institute) & ICTP/MPI & Italy \\
\hline $\begin{array}{l}\text { IPSL (Institut Pierre Simon } \\
\text { Laplace) }\end{array}$ & IPSL & IPSL/IPSL & France \\
\hline
\end{tabular}

Irati at Liedena $\left(1588 \mathrm{~km}^{2}\right)$
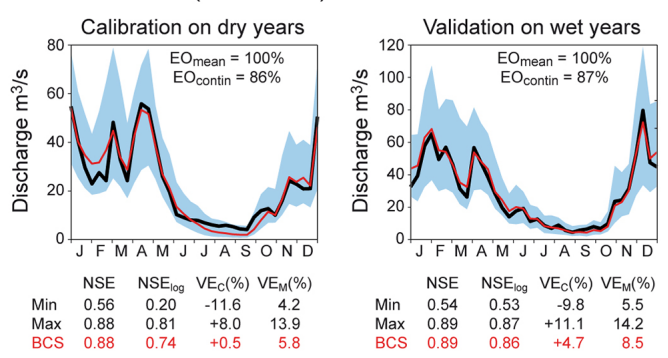

Loukkos at Makhazine $\left(1808 \mathrm{~km}^{2}\right)$
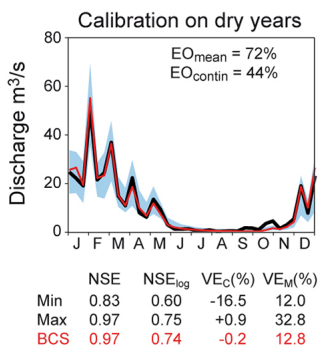

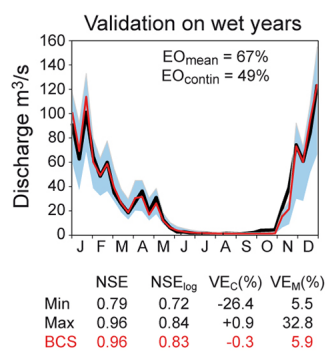

Herault at Laroque $\left(910 \mathrm{~km}^{2}\right)$
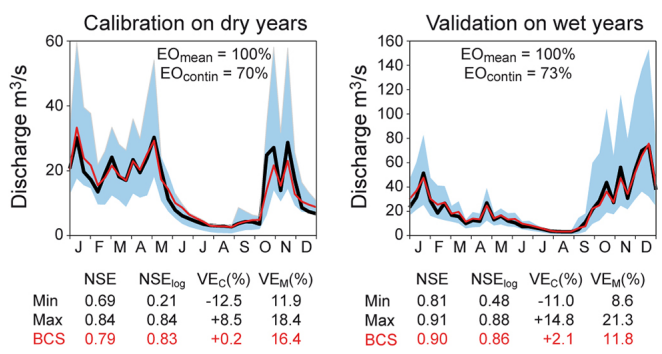

Segre at Seo de Urgel $\left(1265 \mathrm{~km}^{2}\right)$
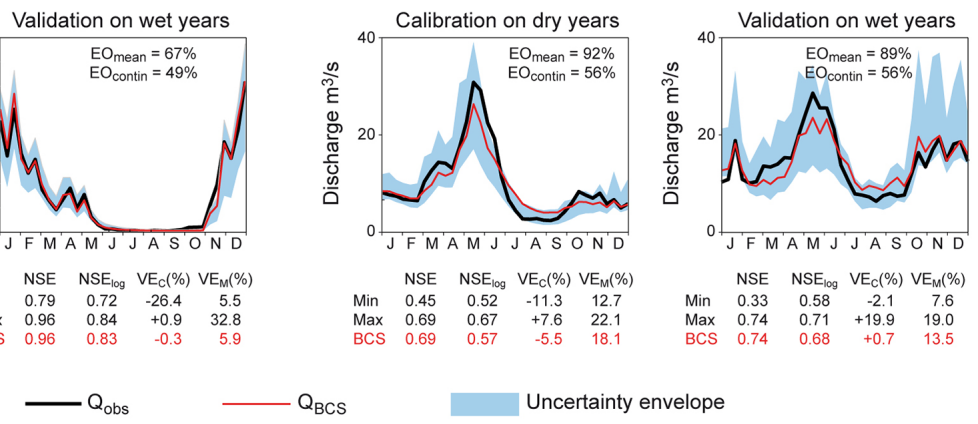

Uncertainty envelope

Figure 2. Hydrological simulation bounds in calibration (dry years) and validation (wet years) over 1986-2005. Minimum and maximum values for each goodness-of-fit criterion are extracted from the Pareto-solutions retained and composing the uncertainty bounds. BSC stands for the solution minimizing the aggregated function $\gamma$ (Eq. 5) among the Pareto-solutions. $\mathrm{EO}_{\text {mean }}$ and $\mathrm{EO}_{\text {contin }}$ stand for the proportion of observations enclosed within the Pareto-bounds over the multi-year period in calibration or validation for the mean and continuous interannual hydrograph respectively.

using a dry calibration sub-period. This led us to retain the Pareto-optimal solutions obtained during the dry calibration sub-period for the prospective simulations.

\subsection{Future climatic trends and uncertainties}

Figure 3 shows that climate projections are convergent regarding temperatures, which could increase by about +1 to $+3{ }^{\circ} \mathrm{C}$ on each basin. In contrast, no clear trends in precipitation could be put in evidence, some RCMs leading to a mean annual precipitation decrease (up to $64 \%$ ), and others to an increase (up to $33 \%$ ). 
Irati at Liedena $\left(1588 \mathrm{~km}^{2}\right)$
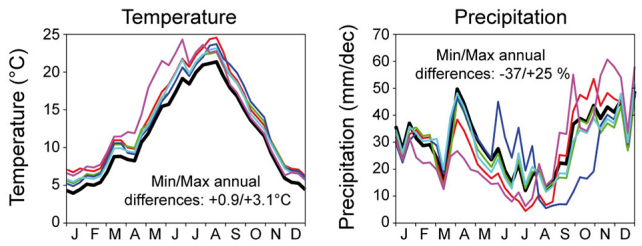

Loukkos at Makhazine $\left(1808 \mathrm{~km}^{2}\right)$
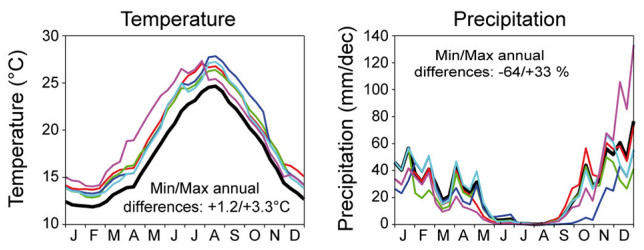

- Obs

- CMCC/CMCC
Herault at Laroque $\left(910 \mathrm{~km}^{2}\right)$
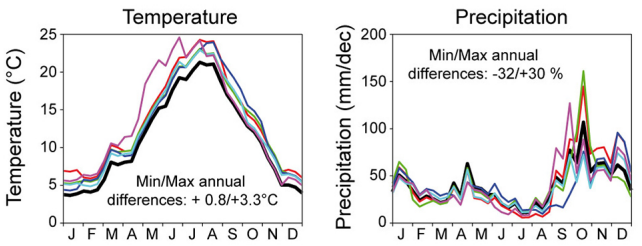

Segre at Seo de Urgel (1 $\left.265 \mathrm{~km}^{2}\right)$
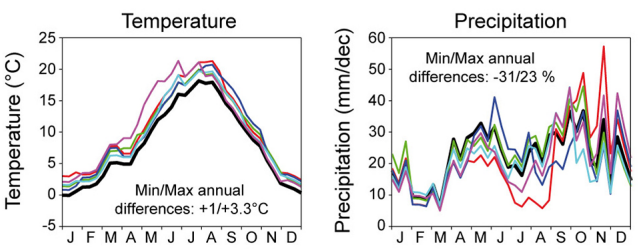

ICTP/MPI

Figure 3. Changes in mean seasonal temperature and precipitation at the 2050 horizon compared to the reference period. The values expressed in ${ }^{\circ} \mathrm{C}$ and $\%$ correspond to the differences between bounds of variation in comparison to mean annual observations of temperature and precipitation.

Irati at Liedena (1 $\left.588 \mathrm{~km}^{2}\right)$

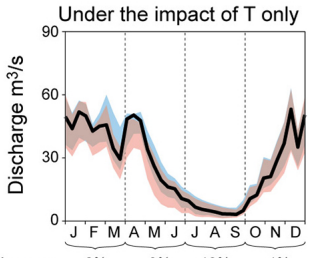

$\begin{array}{llllr}\text { Var. } \max & -6 \% & -9 \% & -10 \% & -1 \% \\ \text { Var. } \min & -8 \% & -26 \% & -30 \% & -11 \%\end{array}$

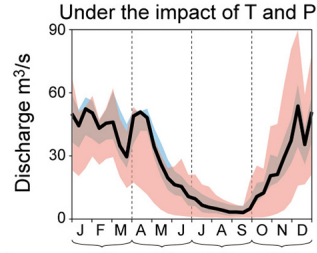

Var. $\max \underbrace{-2 \%}_{-0 \%} \quad+37 \% \quad+47 \%$ $\begin{array}{lrrrr}\text { Var. } \max & -0 \% & -2 \% & +37 \% & +47 \% \\ \text { Var. } \min & -31 \% & -70 \% & -77 \% & -64 \%\end{array}$
Herault at Laroque $\left(910 \mathrm{~km}^{2}\right)$
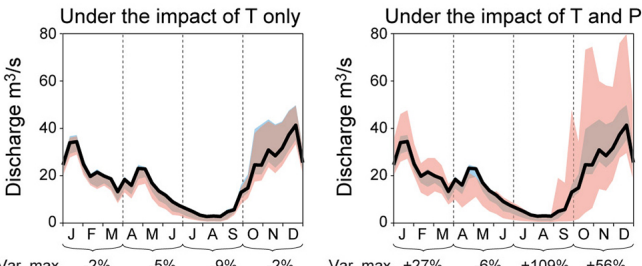

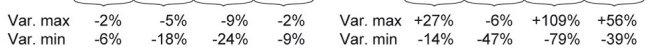

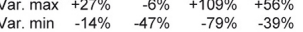

Loukkos at Makhazine (1 $\left.808 \mathrm{~km}^{2}\right)$
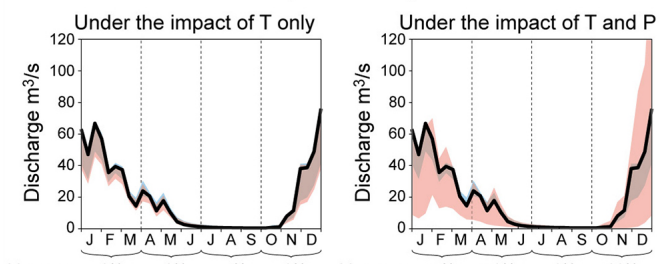

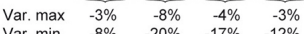

Var. $\max \underbrace{+3 \%}_{+4 \%} \quad \underbrace{+0 \%}_{-0 \%} \quad+96 \%$

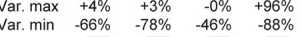

Segre at Seo de Urgel $\left(1265 \mathrm{~km}^{2}\right)$
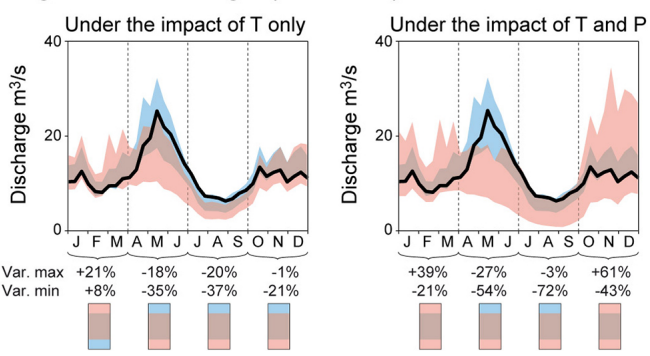

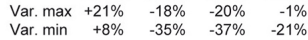

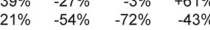

$-Q_{R E F}-B C S$ over the reference period (1986-2005)
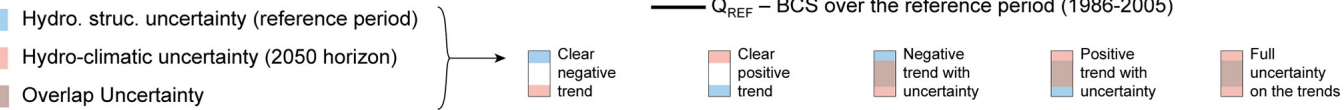

Figure 4. Hydrological scenarios by the 2050 horizon and associated uncertainties.

\subsection{Future hydrological trends and uncertainties}

Figure 4 shows the 2050 hydrological projections, which result from the combination of the hydrological simulation bounds with the range of climate projections.

Hydrological projections based only on temperature (and associated PE) ensemble scenarios generally agree on a runoff decrease during all seasons. Only the snow-dominated Segre basin could experience a runoff increase during winter due to the temperature increase, which could limit solid precipitation and snow stocks. On the opposite, projections mixing temperature and precipitation ensemble scenarios only agree on a possible runoff decrease (2-77\%) during spring on all basins but no clear trend in runoff can be observed 
for the other seasons. This is due to the large overlapping of the hydrological and climatic uncertainty bounds, notably in winter (Fig. 4). Moreover, it should be noted that whatever the type of climate scenarios considered (temperature projections associated or not with precipitation projections), no clear (positive or negative) trend in runoff can be put in evidence for all seasons due to the superposition of the uncertainty bounds between past and future hydrological simulations.

\section{Conclusion and prospects}

This study explored various hydrological projections while accounting for propagation uncertainties that arise from the methods used to generate climate projections and to simulate streamflow responses at the basin scale in the Western Mediterranean. Structural uncertainty associated with hydrological modelling was investigated using a multi-objective calibration approach and a differential split sample test while climate-related uncertainties were considered through an ensemble of recent regional climate projections in the Mediterranean.

Climate projections were shown to be convergent regarding temperatures, which could increase by about +1 to $3{ }^{\circ} \mathrm{C}$ on each basin. In contrast, no clear trends in precipitation could be put in evidence, some RCMs leading to a mean annual precipitation decrease (up to $64 \%$ ), and others to an increase (up to $33 \%$ ). Similar divergences in the precipitation projections from several CMIP5 GCMs were also observed in Southern France and Northern Spain (Grouillet et al., 2015). As a result, hydrological projections based only on temperature ensemble scenarios generally agree on a runoff decrease during all seasons (except in winter for snow-affected basins) while projections mixing temperature and precipitation ensemble scenarios only agreed on a possible trend to runoff decrease (2-77\%) during spring on all basins.

Moreover, it should be noted that whatever the type of climate scenarios considered (temperature projections associated or not with precipitation projections), no clear (positive or negative) trend in runoff could be put in evidence for all seasons due to the superposition of the uncertainty bounds between past and future hydrological simulations. This means that, even if the hydrological uncertainty is limited compared to uncertainty in climate (in particular precipitation) projections, it is still very significant and that the lack of robustness of the hydrological model (due to its model structure and/or to the wrong estimate of its inputs) was a major source of variability among streamflow projections under future climate conditions. Of course, other (or less) objective functions to quantify parameter uncertainty via the Pareto-optimality concept could produce parameter sets yielding to reduced uncertainty bounds. However, tests in that sense showed that a trade-off existed between the simulation bounds and the number of observations they enclosed. Therefore, a greater effort should be invested in improving the robustness of models for climate change impact studies, notably by developing more suitable model structures and proposing calibration procedures that increase their robustness.

In this context, evaluating a wide range of divergent climate projections may also not necessarily provide a useful overview of the possible impact of climate change on water management issues. To develop a didactic demonstration that brings scientists and managers to a reflection on adaptation strategies to climate change, it may be more suitable to limit the analysis to a multi-model ensemble mean of future projections (see e.g. Knutti et al., 2010) or even adopt a modelfree approach relying on a sensitivity analysis under different climate scenarios. Climate-related uncertainties could thus be restrained to the use of basic climate scenarios leading progressively to warmer and drier conditions. For instance, only decreasing trends in precipitation associated with a very probable increase in temperature could be considered to focus impact studies towards a degradation of hydro-climatic conditions according to gradual thresholds. We believe this is of primary importance to improve our knowledge regarding vulnerability and resiliency of hydrological systems under possible climate change.

Acknowledgements. This work was carried out as part of the ANR StaRMIP program (Statistical Regionalization Models Intercomparisons and hydrological impacts Project, 2013-2016), the GICC REMedHE project (2012-2015) funded by the French Ministry of Ecology, Sustainable Development and Energy and the ENVI-Med CLIHMag (Changement cLimatique et Impacts Hydrologiques au Maghreb) project funded by the programme INSUMISTRALS.

\section{References}

Brigode, P., Oudin, L., and Perrin, C.: Hydrological model parameter instability: A source of additional uncertainty in estimating the hydrological impacts of climate change?, J. Hydrol., 476, 410-425, 2013.

Chen, J., Brissette, F. P., Poulin, A., and Leconte, R.: Overall uncertainty study of the hydrological impacts of climate change for a Canadian watershed, Water Resour. Res., 47, W12509, doi:10.1029/2011WR010602, 2011.

Coron, L., Andréassian, V., Perrin, C., Lerat, J., Vaze, J., Bourqui, M., and Hendrickx, F.: Crash testing hydrological models in contrasted climate conditions: an experiment on 216 Australian catchments, Water Resour. Res., 48, W05552, doi:10.1029/2011WR011721, 2012.

Coron, L., Andréassian, V., Perrin, C., Bourqui, M., and Hendrickx, F.: On the lack of robustness of hydrologic models regarding water balance simulation: a diagnostic approach applied to three models of increasing complexity on 20 mountainous catchments, Hydrol. Earth Syst. Sci., 18, 727-746, doi:10.5194/hess-18-7272014, 2014. 
Deb, K., Pratap, A., Agarwal, S., and Meyarivan, T.: A fast and elitist multi-objective genetic algorithm: NSGA-II, IEEE Trans. Evolut. Comput., 6, 182-197, 2002.

Fabre, J., Ruelland, D., Dezetter, A., and Grouillet, B.: Simulating past changes in the balance between water demand and availability and assessing their main drivers at the river basin scale, Hydrol. Earth Syst. Sci., 19, 1263-1285, doi:10.5194/hess-191263-2015, 2015.

Gleckler, P. J., Taylor, K. E., and Doutriaux, C.: Performance metrics for climate models, J. Geophys. Res., 113, D06104, doi:10.1029/2007JD008972, 2008.

Grouillet, B., Fabre, J., Ruelland, D., and Dezetter, A.: Historical reconstruction and 2050 projections of water demand under anthropogenic and climate changes in two contrasted Mediterranean catchments, J. Hydrol., 522, 684-696, 2015.

Hublart, P., Ruelland, D., Dezetter, A., and Jourde, H.: Reducing structural uncertainty in conceptual hydrological modeling in the semi-arid Andes, Hydrol. Earth Syst. Sci. Discuss., 11, 1213712186, doi:10.5194/hessd-11-12137-2014, 2014.

Klemeš, V.: Operational testing of hydrological simulation models, Hydrol. Sci. J., 31, 13-24, 1986.

Knutti, R., Furrer, R., Tebaldi, C., Cermak, J., and Meehl, G. A.: Challenges in combining projections from multiple models, J. Climate, 23, 2739-2758, 2010.

Oudin, L., Hervieu, F., Michel, C., Perrin, C., Andreassian, V., Anctil, F., and Loumagne, C.: Which potential evapotranspiration input for a lumped rainfall-runoff model? Part 2: towards a simple and efficient potential evapotranspiration model for rainfallrunoff modelling, J. Hydrol., 303, 290-306, 2005.

Perrin, C., Michel, C., and Andréassian, V.: Improvement of a parsimonious model for streamflow simulation, J. Hydrol., 279, 275289, 2003.

Quintana-Segui, P., Le Moigne, P., Durand, Y., Martin, E., Habets, F., Baillon, M., Canellas, C., Franchisteguy, L., and Morel, S.: Analysis of near-surface atmospheric variables: validation of the SAFRAN analysis over France, J. Appl. Meteorol. Clim., 47, 92 107, 2008.

Refsgaard, J. C., Madsen, H., Andréassian, V., Arnbjerg-Nielsen, K., Davidson, T. A., Drews, M., Hamilton, D. P., Jeppesen, E., Kjellström, E., Olesen, J. E., Sonnenborg, T. O., Trolle, D., Willems, P., and Christensen, J. H.: A framework for testing the ability of models to project climate change and its impacts, Clim. Change, 122, 271-282, 2014.
Ruelland, D., Brisset, N., Jourde, H., and Oyarzun, R.: Modelling the impact of climatic variability on the groundwater and surface flows from a mountainous catchment in the Chilean Andes, in: Cold Regions Hydrology in a Changing Climate, Proc. 25th IUGG General Assembly, Melbourne, Australia, 28 June-7 July 2011, IAHS Publ. 346, 171-179, 2011.

Ruelland, D., Ardoin-Bardin, S., Collet, L., and Roucou, P.: Simulating future trends in hydrological regime of a large SudanoSahelian catchment under climate change, J. Hydrol., 424-425, 207-216, 2012.

Ruelland, D., Dezetter, A., and Hublart, P.: Sensitivity analysis of hydrological modelling to climate forcing in a semi-arid mountainous catchment, in: Hydrology in a changing world: environmental and human dimensions, Proc. 7th FRIEND-Water Int. Conf., Montpellier, France, 7-10 October 2014, IAHS Publ., 363, 145-150, 2014.

Taylor, K. E., Stouffer, R. J., and Meehl, G. A.: An Overview of CMIP5 and the Experiment Design, B. Am. Meteorol. Soc., 93, 485-498, 2012.

Tramblay, Y., Ruelland, D., Somot, S., Bouaicha, R., and Servat, E.: High-resolution Med-CORDEX regional climate model simulations for hydrological impact studies: a first evaluation of the ALADIN-Climate model in Morocco, Hydrol. Earth Syst. Sci., 17, 3721-3739, doi:10.5194/hess-17-3721-2013, 2013.

Teng, J., Vaze, J., Chiew, F. H. S., Wang, B., and Perraud, J. M.: Estimating the relative uncertainties sourced from GCMs and hydrological models in modeling climate change impact on runoff, J. Hydrometeorol., 13, 122-139, 2012.

Van der Linden, P. and Mitchell, J. F. B. (Eds.): ENSEMBLES: Climate change and its impacts: summary of research and results from the ENSEMBLES project, Met Office Hadley Centre, Exeter, 2009.

Wilby, R. L. and Dessai, S.: Robust adaptation to climate change, Weather, 65, 180-185, 2010. 